\title{
Right Posterior Descending Artery
}

National Cancer Institute

\section{Source}

National Cancer Institute. Right Posterior Descending Artery. NCI Thesaurus. Code C102342.

In an individual with a right-dominant heart, the arterial branch that arises from the distal right coronary artery between the acute marginal artery and the first right posterolateral segment. It supplies the inferior apex of the heart. 